\title{
PATHOLOGICAL DIFFRACTION HALOS
}

\author{
BY \\ W. S. DUKE-ELLDER \\ LONDON
}

RECENT work seems to have established that the coloured halos associated with glaucoma are due to a diffraction phenomenon caused by the corneal oedema occurring in states of raised tension described by Fuchs in 18\$2. It was held that the optical properties of the interlamellar system of the cornea when altered by stretching would produce such an effect, but Koeppe (1920) has shown that the angular diameter of the rings which such a system would produce was $3^{\circ}$ to $3.5^{\circ}$, a value considerably smaller than the measurements of the typical glaucomatous halos $\left(\tau^{\circ}\right.$ to $12^{\circ}$, Elliot, $1923 ; 10^{\circ}$ to $12^{\circ}$, Sheard, $1919 ; 11^{\circ}$ to $16^{\circ}$, Koeppe, 1920). The last-mentioned writer has suggested that they correspond in size with the diffraction necessitated by the fibrillary intersections in the vitreous, but Nordenson (1923) failed to confirm the suggestion experimentally, and the mathematical calculations of Druault (1923), and the optical experiments of Emsley and Fincham (1923) have located the cause of their origin near the anterior surface of the cornea. It would seem that the intraocular fluid is forced into the substance of the cornea in states of raised tension in the same manner as the blood of a hyphaema sometimes insinuates itself here under similar conditions. The fluid appears to collect in the superficial parts of the corneal lamellae beneath Bowman's membrane, tracks along the course of the nerve fibres piercing this membrane, and collects as subepithelial droplets inducing an oedematous state of the corneal epithelium. As light travels through the cornea, on meeting these droplets which differ in their optical properties from the medium in which they lie, it suffers diffraction in the same manner as it is resolved into its component wave-lengths by fluid droplets in the atmosphere in the production of a rainbow, or as occurs when a glass plate is steamed. Alternatively it is possible that the cells themselves, altered by oedema, may be the diffracting bodies.

The validity of this theory would appear to be considerably strengthened if typical glaucomatous halos could be produced in a condition where an oedema of this layer of the cornea occurred without any concomitant rise of tension. This combination is provided in the photophthalmic reaction which follows exposure to ultra-violet light. In the milder degrees of this condition, when the process has not advanced to desquamation of the epithelium, an oedema sometimes occurs; my observations with the slit-lamp 
in animals have shown that it may occasionally attain the dimensions of subepithelial vesicles (1926).

Returning late one night from the laboratory suffering from an attack of photophthalmia contracted through carelessness some six hours previously from exposure to a mercury vapour lamp, my misery was to a considerable extent alleviated by observing a distinct halo round every street lamp. These halos were extremely beautiful, and were composed of inner rings of blue and violet and outer rings of yellow and red with a broad band of green in between. Subsequent examination showed that they were of the glaucomatous type, the angular diameter measured from the red ring was $12^{\circ}$, and they reacted to Druault's and Emsley and Fincham's tests. At the same time the tension of the eyes, as measured by Bailliart's scleral tonometer, was $18 \mathrm{~mm} . \mathrm{Hg}$, and finger pressure upon the eye had no effect upon the brightness or the size of the coloured rings. The distressing photophthalmic symptoms largely disappeared in eight hours, but the eyes remained congested for two days, and during these forty-eight hours the halos remained, gradually getting fainter and larger. This would appear to correspond with the disappearance of the droplets of oedema, since the optical conditions necessitate that the larger droplets cause small diffraction rings.

\title{
REFERENCES
}

Druault, A.-Arch. d'Ophtal., T. XL.. pp. 458, 536, 1923.

Duke-Elder, W. S.-Lancet, Vol. I, p. 1137, 1926.

Elliot, R. H. - A treatise on glaucoma. Oxford Med. Pubs., 2nd edition, p. 168, 1922 ; Amer. Jl. of Ophthal., Vol. VI, p. 1, 1923.

Emsley, H. H., and Fincham, E. F.-Amer. Jl. Physiol. Optics, Vol. IV, p. $247,1923$.

Koeppe, L.-Klin. Monatsbl. f. Augenheilk., Bd. LXV, S. 556, 1920.

Nordenson, W.-Sv. Läk. Handb., 1923.

Sheard, C.-Amer. Jl. of Ophthal., Vol. II, p. 185, 1919.

\section{DIRECT OPHTHALMOSCOPY IN HIGH MYOPIA}

\author{
BY \\ Alexander GarRow, M.D. \\ GLASGOW
}

THE examination of the fundus in myopia of high degree by direct ophthalmoscopy presents considerable difficulty and one has often to be satisfied with the indirect method. This has obvious drawbacks when one wishes to study minute details. Under such circumstances I have found that it is most helpful to make the direct examination with the patient wearing his glasses.

After I had made use of this method with increasing benefit for some time I looked through the chapters on ophthalmoscopy in a 